Available online on 15.01.2021 at http://jddtonline.info
O 2011-21, publisher and licensee JDDT, This is an Open Access article which permits
unrestricted non-commercial use(CC By-NC), provided the original work is properly cited

Open Access Full Text Article

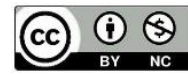

Research Article

\title{
Formulation and Evaluation of Bi-Layer Tablets of Ketorolac Tromethamine
}

\author{
Dhaval M. Patel ${ }^{*}$, Riddhi Trivedi ${ }^{1}$, Hardik Patel ${ }^{2}$ \\ ${ }^{1}$ Professor, SAL Institute of Pharmacy, Ahmedabad, Gujarat, India \\ ${ }^{2}$ Shri Sarswati Institute of Pharmaceutical Sciences, Gandhinagar, Gujarat, India
}

Article Info:

Article History:

Received 19 Nov 2020;

Review Completed 20 Dec 2020

Accepted 28 Dec 2020;

Available online 15 Jan 2021

Cite this article as:

Patel DM, Trivedi R, Patel H, Formulation and Evaluation of Bi-Layer Tablets of Ketorolac

Tromethamine, Journal of Drug Delivery and

Therapeutics. 2021; 11(1):36-41

DOI: http://dx.doi.org/10.22270/jddt.v11i1.4487

*Address for Correspondence:

Dhaval M. Patel, Professor, SAL Institute of Pharmacy, Ahmedabad, Gujarat, India

\section{Abstract}

The objective of the present study was to develop and evaluate bi-layer tablets of Ketorolac tromethamine, a nonsteroidal antiinflammatory drug with short half-life, that are characterized by initial burst drug release in the stomach and comply with the release requirements of sustained-release products. Each of the proposed bi-layer tablets is composed of an immediate-release layer and a sustained-release layer, anticipating rapid drug release that starts in the stomach to rapidly alleviate the symptoms and continues in the intestine to maintain protracted analgesic effect. Gastro retentive Bi-Layer tablets of Ketorolac Tromethamine were prepared by using hydrophilic polymers with direct compression on floating - matrix technology and evaluated. Ketorolac tromethamine is freely soluble in water, so it is suitable to develop it as gastro retentive bi-layer tablets using hydrophilic polymers. The developed formulation is equivalent to calculated theoretical drug profile in view of its in vitro release. Immediate release layer was prepared by using dry granulation method in which ac-di sol used as a disintigrant for immediate release of drug. Sustained release layer formulated by using HPMC as release retardant, two grades of HPMC that are HPMC K4M and HPMC K100M used to get sustained release profile for $24 \mathrm{hr}$. Various trial batches are taken to get desired release profile. Ketorolac tromethamine release from the developed floating formulation followed Higuchi model and nonFickian diffusion is found to be the main mechanism of drug release. The manufacturing procedure was found to be reproducible and formulations were stable after one month of stability studies.

Keywords: FTIR; Gastro retentive bilayer; ketorolac tromethamine; in vitro release; stability; higuchi.

\section{INTRODUCTION}

Ketorolac tromethamine (KET) is a nonsteroidal antiinflammatory drug (NSAID) with extremely potent antiinflammatory and analgesic activities. It is commercially available in the form of rapid-release tablets $(10 \mathrm{mg})$, and parenteral formulations $(30 \mathrm{mg} / \mathrm{ml})$. Ketorolac tromethamine decreases inflammation, pain, and fever through inhibition of prostaglandin synthesis. However, ketorolac tromethamine's usefulness is limited due to its short half-life 5.3 hours. Its pka value is 3.49 , $\mathrm{PH}$ of $1 \%$ solution in water is 5.7. Bi-layer tablets are tablets made by compressing several different granulations fed into a die in succession, one on top of another, in layers. Each layer comes from a separate feed frame with individual weight control. Rotary tablet presses can be set up for two or three layers. The advantages of bi-layer tablets are (1) Incompatible substances can be separated by formulating them in separate layers as a two-layer tablet or separating the two layers by a third layer of an inert substance as a barrier between the two. (2) Two layer tablets may be designed for sustained release-one layer for immediate release of the drug and the second layer for extended release, thus maintaining a prolonged blood level. (3) Layers may be colored differently to identify the product. ${ }^{1-5}$

\section{MATERIALS AND METHODS}

\section{Drug Identification by FTIR}

The Fourier transform infrared spectrum of moisture free powdered sample of KET was recorded on IR spectrophotometer by potassium bromide $(\mathrm{KBr})$ pellet method. The range of spectra was found to be600 to 4000 $\mathrm{cm}^{-1}$.The characteristics peaks of different functional group were compared with reported standard peak. 6

\section{Physical Characteristics of KET}

\section{Flow Properties 7}

\section{Bulk density (B.D.) and tapped density (T.D.)}

An accurately weighed quantity of the blend (W), was carefully poured into the graduated cylinder and the volume $\left(V_{o}\right)$ was measured. Then the graduated cylinder with lid, set into the density determination apparatus (Tapped Density Apparatus). The density apparatus was set for 100 taps and after that the volume $\left(\mathrm{V}_{\mathrm{f}}\right)$ was measured which was tapped 
volume. The bulk density and tapped density were calculated by using the following formulas.

Bulk density $=\mathrm{W} / \mathrm{V}_{0} \quad$ Tapped density $=\mathrm{W} / \mathrm{V}_{\mathrm{f}}$

\section{Compressibility index (CI) / Carr's index}

It was obtained from bulk and tapped densities. It was calculated by using the following formula.

$$
\% \text { Carr's index }=\text { (T.D. }- \text { B.D. } \div \text { T.D. }) \times 100
$$

\section{Hausner's ratio}

Hausner's ratio is a number that is correlated to the flow ability of a powder. It is measured by ratio of tapped density to bulk density.

$$
\text { Hausner's ratio }=(\text { Tapped density } \div \text { Bulk Density })
$$

\section{Angle of repose}

Angle of repose of powder was determined by the funnel method. Accurately weight powder blend were taken in the funnel. Height of the funnel was adjusted in such a way the tip of the funnel just touched the apex of the powder blend. Powder blend was allowed to flow through the funnel freely on to the surface. Diameter of the powder cone was measured and angle of repose was calculated using the following equation.

$$
\operatorname{Tan} \theta=\mathrm{h} / \mathrm{r}
$$

\section{Calculation of total dose 8}

The loading dose \& maintenance dose of Ketorolac Tromethamine Bilayer tablet was calculated by following equation using available pharmacokinetic data.

$\mathrm{Dt}=$ Dose $(1+0.693 \times \mathrm{t} / \mathrm{t} 1 / 2)$

Where, $\mathrm{Dt}=$ Total dose of drug; Dose $=$ dose of immediate release part $(5 \mathrm{mg})$; $\mathrm{t}=$ time (hours) during which the sustained release is desired (23.5 hours); $t 1 / 2=$ half-life of drug (5.3 hours) Dt $=5(1+0.693 \times 23.5 / 5.3)=20 \mathrm{mg}$ Hence formulation should contain total dose $20 \mathrm{mg}$ with $5 \mathrm{mg}$ as loading dose, dose of immediate release part and $16 \mathrm{mg}$ is maintenance dose, dose of sustained release part.

\section{Formulation and Evaluation of Bi-Layer Gastro Retentive Tablet}

Composition of immediate release formulation was shown in Table 1. Different immediate release tablets formulations were prepared by direct compression technique. All the powders were passed through 80 mesh sieve. Required quantity of drug and various super disintegrating agents like sodium starch glycolate, and ac-di-sol were mixed thoroughly. Talc and magnesium stearate were finally added as glidant and lubricant respectively. The blend was compressed using $8 \mathrm{~mm}$ punch in Rotary punching tablet machine. For formulation of sustained release tablet, composition of preliminary batches is shown in Table 1 . The Gastro retentive layer is composed of maintenance dose $(15$ $\mathrm{mg}$ ) of drug and different grade of hydroxyl propyl methyl cellulose (HPMC) like HPMC K4M, HPMC K100M. Other ingredients were Sodium bicarbonate $\left(\mathrm{NaHCO}_{3}\right)$, microcrystalline cellulose, lactose and talc, magnesium stearate. All the ingredients were mixed thoroughly and finally compressed with help of Rotary Tablet punching machine. Prepared tablets were evaluated in terms of in-vitro dissolution profile and physical parameters. Each formulation composed of different concentration of sodium bicarbonate and citric acid in order to optimize concentration of gas generating agent. Composition of Bilayer gastro retentive tablet was given in Table 1. Optimized batch of immediate release layer as well as gastro retentive layer was selected. First, immediate release formulation placed on cavity of die and compressed then finally sustained release layer (gastro retentive layer) were placed. of KET bilayer tablet was performed. Tablet was then evaluated for various physical parameters, weight variation, friability and hardness, in-vitro dissolution profile, swelling index, kinetic

\begin{tabular}{|c|c|c|c|c|c|c|}
\hline & F1 & F2 & F3 & F4 & F5 & F6 \\
\hline \multicolumn{7}{|c|}{ Immediate release layer } \\
\hline KET & 5 & 5 & 5 & 5 & 5 & 5 \\
\hline Ac-di-sol & - & - & - & 2.5 & 5 & 7.5 \\
\hline Sodium Starch Glycolate (SSG) & 2.5 & 5 & 7.5 & - & - & - \\
\hline Dicalcium Phosphate (DCP) & 89.5 & 87 & 84.5 & 89.5 & 87 & 84.5 \\
\hline Magnesium stearate & 1 & 1 & 1 & 1 & 1 & 1 \\
\hline Talc & 2 & 2 & 2 & 2 & 2 & 2 \\
\hline \multicolumn{7}{|c|}{ Sustained release layer } \\
\hline KET & 15 & 15 & 15 & 15 & 15 & 15 \\
\hline HPMCK100M & 80 & 50 & 40 & 25 & - & - \\
\hline HPMCK4M & - & - & 40 & 25 & 80 & 50 \\
\hline $\mathrm{NaHCO}_{3}$ & 35 & 35 & 35 & 35 & 35 & 35 \\
\hline Miro Crystalline cellulose (MCC) & 64 & 94 & 64 & 94 & 64 & 94 \\
\hline Magnesium stearate & 2 & 2 & 2 & 2 & 2 & 2 \\
\hline Talc & 4 & 4 & 4 & 4 & 4 & 4 \\
\hline
\end{tabular}
modelling, drug release mechanism and stability study.

Table 1: Composition of different batches of bi-layer Tablets of KET

\section{In-vitro dissolution studies}

The release rate of KET from bi-layer gastro retentive tablets was determined using United State Pharmacopoeia (USP) XXIV dissolution testing apparatus II (paddle method). The dissolution test was performed using $900 \mathrm{ml}$ of $0.1 \mathrm{~N} \mathrm{HCl}$
(pH 1.2), at $37 \pm 0.5^{\circ} \mathrm{C}$ and $50 \mathrm{rpm}$. A sample (10 ml) of the solution was withdrawn from the dissolution apparatus at an interval of every hr for initially three hours and then every two hours till $24 \mathrm{hrs}$. The samples were replaced with fresh dissolution medium of same quantity. The samples were filtered through a $0.45 \mu$ membrane filter. Absorbance 
of these solutions was measured at $322 \mathrm{~nm}$ using a Shimadzu UV-1601 spectrophotometer. Cumulative percentage of drug release was calculated using an equation obtained from a standard curve. 9-11

\section{Comparison of dissolution profiles}

The similarity factor $\left(f_{2}\right)$ given by SUPAC guidelines for modified release dosage form was used as a basis to compare dissolution profile. The dissolution profiles are considered to be similar when $f_{2}$ is between 50 and 100 . The dissolution profiles of products were compared using $f_{2}$. This similarity factor is calculated by following formula,

$$
f_{2}=50 \log \left\{\left[1+\frac{1}{n} \sum_{t=1}^{n}\left(R_{t}-T_{t}\right)^{2}\right]^{-0.5} \times 100\right\}
$$

Where, $n$ is the number of dissolution time and $R_{j}$ and $T_{j}$ are the reference and test dissolution values at time. Theoretical release profile of sustained release shown in Table 2.11

Table 2: Theoretical release profile of sustained release tablet

\begin{tabular}{|c|c|}
\hline Time (hrs) & Theoretical release profile \% \\
\hline 0 & 0 \\
\hline 1 & 4.25 \\
\hline 2 & 8.5 \\
\hline 4 & 17.01 \\
\hline 6 & 25.52 \\
\hline 8 & 34.00 \\
\hline 10 & 42.53 \\
\hline 12 & 51.04 \\
\hline 14 & 59.54 \\
\hline 16 & 68.00 \\
\hline 18 & 76.53 \\
\hline 20 & 85.00 \\
\hline 22 & 93.53 \\
\hline 23.5 & 99.92 \\
\hline
\end{tabular}

\section{Ex-Vivo Bio-adhesion study}

Tablet bio-adhesion studies were done using goat stomach mucosa. The apparatus consisted of a modified double beam physical balance in which the right pan was replaced by a glass slide with copper wire and additional weight, to make the right side weight equal with left side pan. Another glass arrangement of suitable height and diameter was prepared, which was kept in beaker filled with $0.1 \mathrm{~N} \mathrm{HCl}(\mathrm{pH} \mathrm{1.2)}$, and then placed below the right side of the balance. The detachment force, i.e. the force required for separating the tablet from the tissue surface was determined. The tablet was lowered onto the mucosa under a constant weight of $5 \mathrm{~g}$ for a total contact period of $1 \mathrm{~min} .{ }^{12}$

\section{Swelling index}

The swelling index of tablets was determined in $0.1 \mathrm{~N} \mathrm{HCl}$ (pH 1.2) at room temperature. The swollen weight of the tablets was determined at predefined time intervals. The swelling index was calculated by the following equation. Determinations were made in triplicate.

$$
\text { swelling index }=W t-W o / W t
$$

Where, $\mathrm{W}_{0}$ is the initial weight of tablet, and $\mathrm{W}_{\mathrm{t}}$ is the weight of the tablet at time t. ${ }^{13}$

\section{Kinetic modeling and mechanism of drug release}

Data obtained form in vitro drug release studies were fitted to dissocalculation software. The kinetic models used are zero order, first order, Korshmers and papps, Hexon crowell, and Higuchi equation. 14

\section{Stability study of the optimized batch}

Bi-layer gastro retentive tablets of KET formulated in the present study were subjected to accelerated stability studies at $40{ }^{\circ} \mathrm{C}$ and $75 \% \mathrm{RH}$ for 1 month in a humidity chamber. The tablets of best batch were packed in aluminum foil pouch and analyzed for floating behavior and in-vitro drug release study. 14-15

\section{RESULTS AND DISCUSSION}

\section{Identification of KET by FTIR}

KET is identified by FTIR shown in Figure 1.

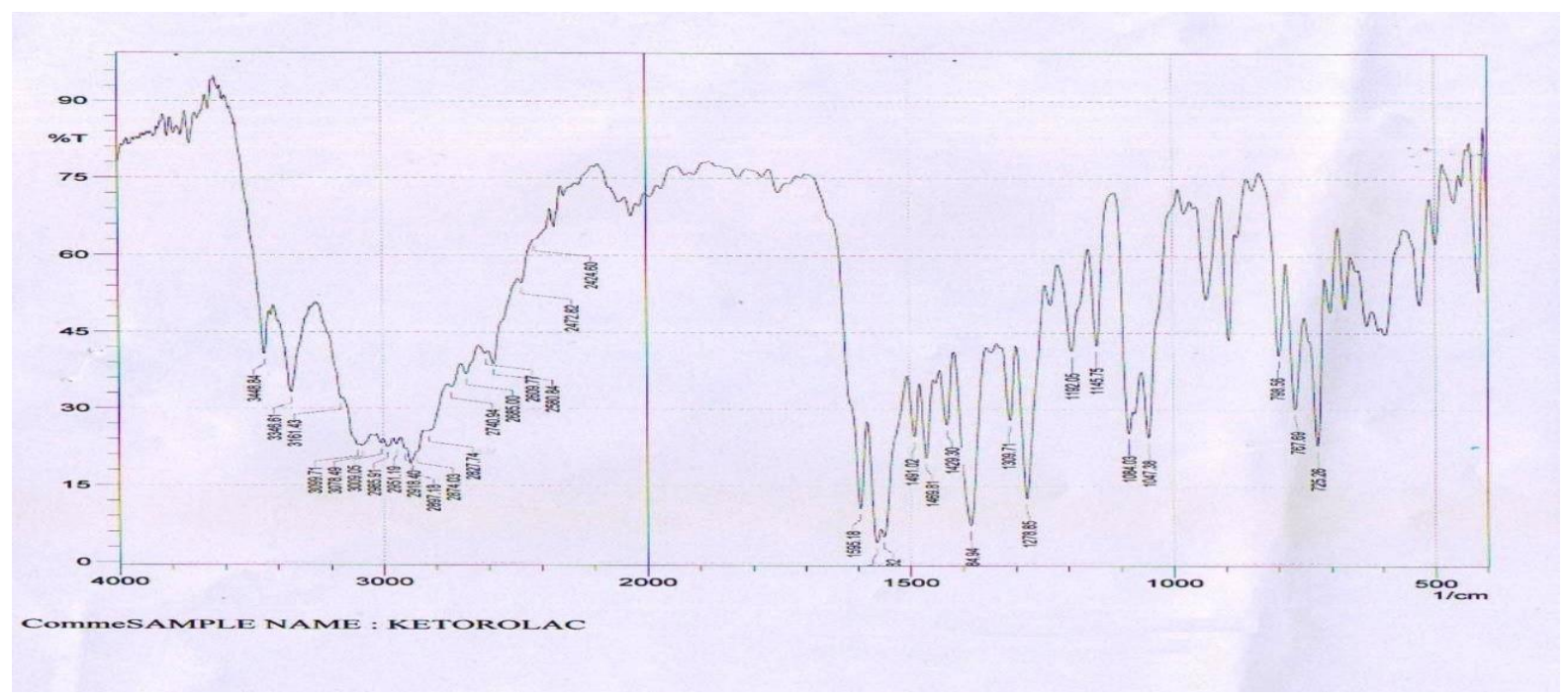

Figure 1: FTIR OF KET 
Preparation of Bi-layer gastro retentive tablet of Ketorolac tromethamine

The photograph of bi-layer tablet of KET in which bottom layer is floating layer which is composed of maintenance dose of KET, upper layer (pink in color) is immediate release layer which is composed of loading dose of KET is shown in Figure 2.

\section{Flow Properties}

The bulk density of Ketorolac tromethamine was 0.355 $\mathrm{gm} / \mathrm{ml}$, tapped density was $0.448 \mathrm{gm} / \mathrm{ml}$. Hausner's ratio and Carr's Index values were 1.261 and 20.690 respectively, which indicates the higher compressibility. Further flow property was determined by Angle of repose, and it was $25.66^{\circ}$, which shows that drug has good flow Properties. (Table 3)

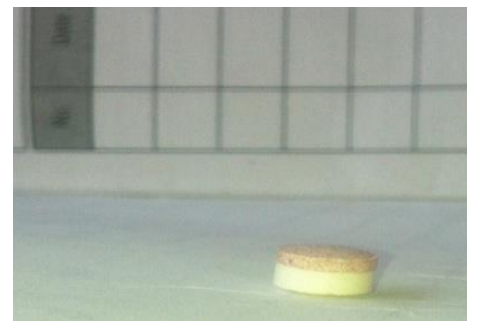

Figure 2: Bi-layer tablet of KET

Table 3: Flow properties of KET

\begin{tabular}{|c|c|c|c|c|}
\hline $\begin{array}{c}\text { Bulk Density } \\
\text { (gm/ ml) }\end{array}$ & $\begin{array}{c}\text { Tapped Density } \\
\text { (gm/ ml) }\end{array}$ & $\begin{array}{c}\text { Compressibility } \\
\text { Index (\%) }\end{array}$ & Hausner's Ratio & $\begin{array}{c}\text { Angle of Repose } \\
\left(\mathbf{(}^{\circ}\right)\end{array}$ \\
\hline 0.355 & 0.448 & 20.690 & 1.261 & 25.66 \\
\hline
\end{tabular}

\section{Post Compression Parameters of Bi-layer Tablets}

All the tablet formulations showed acceptable properties and complied with the in-house specifications for weight variation, hardness and friability. Results of these studies are shown in Table 4.

Table 4: Post compression parameters of prepared tablets

\begin{tabular}{|c|c|c|c|}
\hline Batches & $\begin{array}{c}\text { Weight variation (mg) } \\
\text { (n=20) }\end{array}$ & $\begin{array}{c}\text { Hardness (kg/cm } \mathbf{~}) \\
\mathbf{( n = 1 0 )}\end{array}$ & $\begin{array}{c}\text { Friability (\%) } \\
\mathbf{( n = 1 0 )}\end{array}$ \\
\hline F1 & $205 \pm 2.88$ & $4.8 \pm 0.124$ & $0.92 \pm 0.0028$ \\
\hline F2 & $200 \pm 2.51$ & $4.5 \pm 0.057$ & $0.95 \pm 0.0023$ \\
\hline F3 & $200 \pm 2.51$ & $5 \pm 0.15$ & $0.83 \pm 0.0018$ \\
\hline F4 & $190 \pm 2.88$ & $5.5 \pm 0.057$ & $0.68 \pm 0.00149$ \\
\hline F5 & $200 \pm 2.51$ & $5 \pm 0.15$ & $0.826 \pm 0.0018$ \\
\hline F6 & $195 \pm 2.88$ & $5.5 \pm 0.057$ & $0.79 \pm 0.0015$ \\
\hline
\end{tabular}

\section{In- Vitro Dissolution Profile}

In vitro dissolution behaviour of bi-layer tablets is shown in Figure 3. In different batches of bi-layer tablets, drug release was affected by hardness. It was found that time for $80 \%$ drug release was increased due to increase in hardness. Therefore intermediate hardness $\left(5 \mathrm{~kg} / \mathrm{cm}^{2}\right)$ was considered to be optimum for formulation of bi-layer tablets.

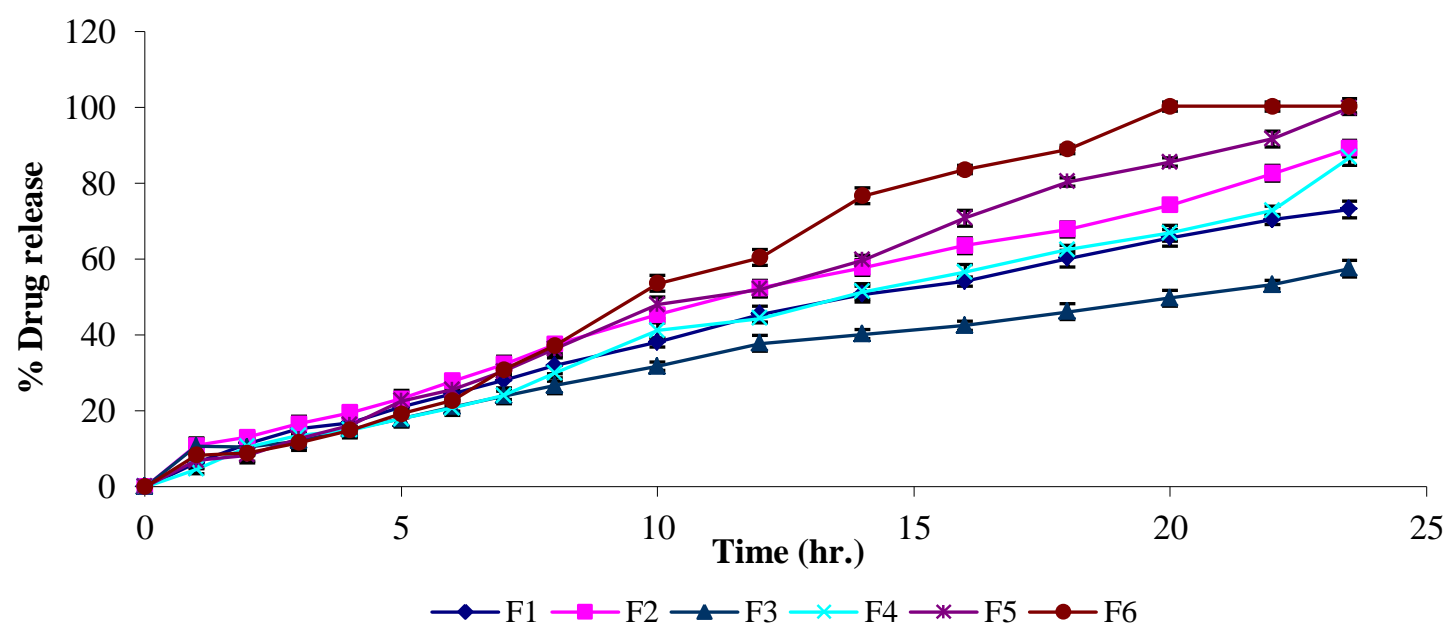

Figure 3: In-vitro drug release profile Bi-layer tablet formulations of KET 


\section{Comparison of dissolution profiles}

The similarity factor, $f_{2}$, given by SUPAC guidelines for modified release dosage form was used as a basis to compare dissolution profiles. The dissolution profiles are considered to be similar when $f_{2}$ is between 50 and 100 . The dissolution profiles of products were compared using a similarity factor $\left(f_{2}\right)$. This similarity factor is a logarithmic reciprocal square root transformation of one plus the average mean squared (the average sum of squares) differences of drug percent dissolved between the test and reference products over all time points. In vitro drug release profile of all batches was compared with theoretical drug release profile. The result is shown in Table 5, which indicates that, all batches shows good similarity to theoretical release profile. Amongst these, Batch F5 showed the highest $f_{2}$ of 85.126 .

Table 5: Comparison of dissolution profiles of bi-layer tablet batches with theoretical release profile and Ex-vivo Mucoadhesion study

\begin{tabular}{|c|c|c|c|c|}
\hline \multirow{2}{*}{ Formulation code } & \multicolumn{3}{|c|}{ Dependent variables } & Ex-vivo Mucoadhesion study \\
\cline { 2 - 5 } & $\mathbf{Q}_{\mathbf{2 4}}$ & $\mathbf{t}_{\mathbf{8 0}}$ & $\boldsymbol{f}_{\mathbf{2}}$ & Force required (gms) \\
\hline F1 & 73.145 & $>24$ & 50.709 & 7 \\
\hline F2 & 89.254 & 22 & 65.691 & 10 \\
\hline F3 & 57.539 & $>24$ & 38.305 & 6 \\
\hline F4 & 86.835 & 22.5 & 55.619 & 11 \\
\hline F5 & 99.922 & 18 & 85.126 & 6 \\
\hline F6 & 100.342 & 18 & 77.479 & 7 \\
\hline
\end{tabular}

\section{Ex-vivo bio adhesion study}

The result of bio adhesion study is shown in Table 5. F1 and F2 batch showed bioadhesive force $12 \mathrm{gm}$ and $7 \mathrm{gm}$ respectively. The values indicate that the bioadhesive force increased significantly as the concentration of HPMCK100M bioadhesive polymer increased. The highest bioadhesive strength was observed in formulation $\mathrm{F} 1$ and $\mathrm{F} 5$ containing HPMCK100M and HPMCK4M. F1 and F5 batch showed bio adhesive force $12 \mathrm{gm}$ and $11 \mathrm{gm}$ respectively. Tablets of formulations F3 showed intermediate bioadhesion force whereas formulations F2, F4 and F6 showed least bioadhesion strength. In case of F1 formulation, high bioadhesive strength of HPMCK100M was retard drug release. Therefore, formulation F5 was selected for further preparation of bilayer tablets.

\section{Swelling index study}

Tablets composed of polymeric matrices build a gel layer around the tablet core when they come in contact with water. This gel layer governs the drug release. Kinetics of swelling is important because the gel barrier is formed with water penetration. Swelling is also a vital factor to ensure floating. To obtain floating, the balance between swelling and water acceptance must be restored. The swelling index of the best batch at different time intervals is mentioned in Table 6, which may be because of high viscosity and high water retention property of HPMC polymer.
Table 6: Swelling study of batch F5

\begin{tabular}{|c|c|}
\hline $\begin{array}{c}\text { Time } \\
\text { (hrs) }\end{array}$ & $\begin{array}{c}\text { Swelling } \\
\text { index }\end{array}$ \\
\hline 6 & 1.831 \\
\hline 12 & 2.184 \\
\hline 18 & 3.157 \\
\hline 24 & 3.31 \\
\hline
\end{tabular}

\section{Kinetic modelling and mechanism of drug release}

The dissolution profile of the best batch was fitted to zeroorder, first-order, Higuchi and Hixon-Crowell, and korsmeyer models to ascertain the kinetic modeling of drug release. To analyze the mechanism of drug release from the matrix tablets, the release data of best Batch F5 were fitted in all models. (Table 7) The dissolution profile of the best batch was fitted to zero-order, first-order, Higuchi and Hixon-Crowell, and korsmeyer models to ascertain the kinetic modeling of drug release. To analyze the mechanism of drug release from the matrix tablets, the release data of best batch F5 were fitted Higuchi model. Further to characterize the release mechanisms of KET from optimize formulation, the dissolution data were subjected to the Higuchi model. The ' $n$ ' values for F5 formulation was 0.61, indicating that the release mechanism was non-Fickian or anomalous release in. It can be inferred that the release was dependent on both drug diffusion and polymer relaxation. 16

Table 7: Kinetic modeling data of batch F5

\begin{tabular}{|c|c|c|c|c|c|}
\hline Model & Zero-order & First-order & Higuchi plot & Hixon Crowell & Korsmeyer \\
\hline $\mathbf{R}^{\mathbf{2}}$ & 0.9961 & 0.9664 & 0.9995 & 0.9162 & 0.9983 \\
\hline Slope & 10.025 & 0.0765 & 38.684 & 3.3417 & $0.6135(\mathrm{n})$ \\
\hline Intercept & 20.206 & 1.432 & -12.675 & 26.598 & -0.5657 \\
\hline
\end{tabular}




\section{Stability study of the optimized batch}

The promising formulation F5 was subjected to short term stability study by storing the formulation at $40^{\circ} \mathrm{C} / 75 \%$ R.H. for 1 month. After 1 month the tablet was again analyzed for the in-vitro drug release profile and floating behaviour. No significance change was observed in in-vitro drug release profile and the floating behaviour of tablet after stability studies. The results of stability studies are shown in Figure 4. 17,18

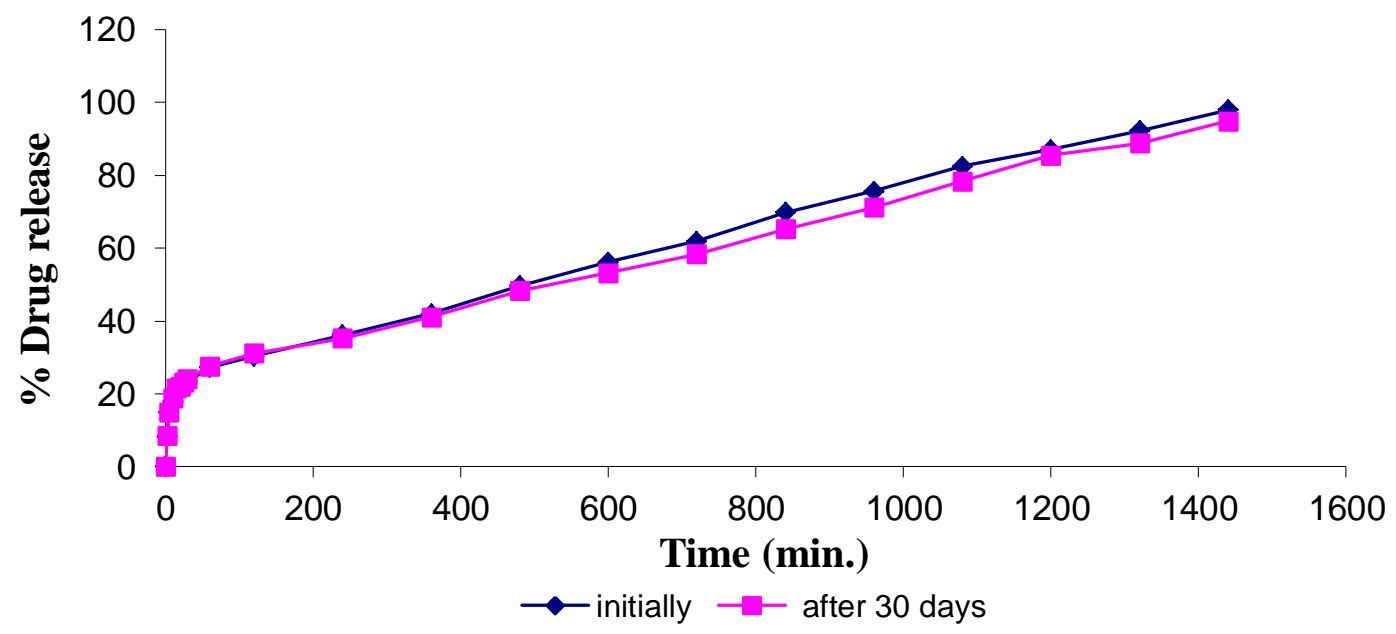

Figure 4: In-vitro drug release profile of optimized batch F5 after stability study

\section{CONCLUSION}

Bilayer tablets of KET containing sustained release layer and immediate release layer were successfully formulated. Release was found to follow zero, first, Higuchi, Hixoncrowel and krossmayer-peppas models. All the formulation batches tested for physical parameters like weight variation, hardness and friability all were found to be within the USP limits. The optimized formulations were found to be stable at all the stability conditions. During stability studies, no significant variation (1-4\%) in drug release was observed. Total floating time of optimized batch was found to be more than $24 \mathrm{hrs}$. This is due to the floating as well as good sustained release properties of HPMC polymer. $40 \%$ concentration of HPMC K4M was optimized for bi-layer gastro retentive tablet of KET.

\section{Conflict of Interest Statement}

The authors declare that the research was conducted in the absence of any commercial or financial relationships that could be construed as a potential conflict of interest.

\section{REFERENCES}

1. Buckley, M.T., Brogden, R.N. Ketorolac: A review of its pharmacodynamics and pharmacokinetics properties and therapeutic potential. Drugs. 1990; 39:86-109.

2. Lieberman, H., Lachman, L., Schwetz, J.B. Pharmaceutical dosage forms. 2nd edition. 2: 179-181.

3. The merck index, 12 th edition: 5324 .

4. Drug Today, 2006; 1: 210.

5. Patel, D.M., Patel, A.B., Trivedi, R.D., Parmar, V.J., Bangoriya, U.V Evaluation of the effect of hydroalcoholic extract of Cassia occidentalis leaves in neutrophil adhesion test in rats. JDDT. 2019; 9 (4s):1218-1221.

6. Metkar, V., Kumar, A., Pant, P., Pal, D., Sahu, S., Shurngarpure, M., Madhusudan, D. Formulation development and evaluation of Bilayer tablets of Lornoxicam. IJDDR. 2012; 4 (2):173-179.

7. Wells, J. Pharmaceutical preformulation: The physiochemical properties of drug substances. In: Aulton ME, editor. Pharmaceutics the science of dosage form design. London: Churchill Livingstone; 2002; 247.

8. Girish, S.S. , Devendra, K.J., Dhananjay, M.M. Preparation and in vitro evaluation of bilayer and floating-bioadhesive tablets of rosiglitazone maleate. Asian Journal of Pharmaqceutical Sciences. 2007; 2(4):161-169.

9. Singh, S.K., Srinivasan, K.K., Gowthamarajan, K., Narayan, G.B. Development and validation of discriminatory dissolution procedure for poorly soluble glyburide. Asian Journal of Pharmaceutics. 2010; 4:205-212.

10. Patel, A., Patel, D., Patel, D., Sheth, A., Shah, U.J. Method Development and Validation for Simultaneous Estimation of Benidipine Hydrochloride and Metoprolol Succinate in Tablet. JDDT. 2019; 9 (6s):28-33.

11. Trivedi, R.D., Shah, S.K. "Formulation and Evaluation of Mucoadhesive Nasal Microspheres of Hydralazine Hydrochloride" The Journal of medical research, 2018,

12. Costa, P., Manuel, S.L. Modeling and comparison of dissolution profiles. Eur. J. of Pharma.Sci. 2001; 12:123-133.

13. Ravindran, V.K., Vasa, S., Banji, D. Comparative Study of Mucoadhesive Polymers Carbopol 974P and Sodium Carboxy Methyl Cellulose for single unit dosage of Imatinib Mesylate. Malay J.Pharm. Sci. 2012; 10:61-77.

14. Colombo, P., Bettini, R., Peppas, N.A. Observation of swelling process and diffusion front position during swelling in Hydroxypropylmethylcellulose (HPMC) matrices containing a soluble drug. J. Control. Release. 1999; 61:83-91.

15. Momin, M.M., Kane, S., Abhang, P. Formulation and evaluation of bilayer tablet for bimodal release of venlafaxine hydrochloride. Front. Pharmacol. 2015; 6(144):1-10. doi: 10.3389/fphar.2015.00144

16. Dave, R., Patel, R. "Preparation and characterization of doxorubicin $\mathrm{HCl}$ loaded chitosan nanoparticles by w/o emulsion method" International Journal Of Pharmacy \& Life Sciences, 2013; 4(2).

17. Dave, R.M., Patel, R., Chauhan, H. "Effect of cryoprotectant on lyophlisation of doxorubicin -HCl loaded chitosan nanoparticles" International Journal Of Pharmacy \& Life Sciences, 2012; 3(6).

18. Patel, A.B., Patel, D.R., Patel, D.M., Patel, K.S., Patel, P. Stability indicating HPLC method development and validation of Enrofloxacin and Bromhexine $\mathrm{HCl}$ in combined dosage form. Aegaeum Journal. 2020; 8 (5):443-457. 